\title{
The practice of cardiothoracic surgeons in the perioperative staging of non-small cell lung cancer
}

In this issue (p 3) Tsang and Watson report the results of their postal survey of the investigations used by thoracic and cardiothoracic surgeons in the United Kingdon in the preoperative and intraoperative assessment of non-small cell lung cancer. The questionnaire was necessarily brief and simple, and some of the results can be criticised as being shallow and ambiguous. The overall conclusion is inescapable, however-almost half of the surgeons who replied did not assess the mediastinum thoroughly before thoracotomy, and over half did not evaluate this assessment intraoperatively by excising or sampling macroscopically normal mediastinal lymph nodes.

The most obvious result of this policy is the continued high incidence of futile thoracotomies. The annual returns of the Society of Cardiothoracic Surgeons of Great Britain and Ireland (unpublished 1985) show that almost $20 \%$ of thoracotomies are "open and close." This figure is an average, and fell by only $2-3 \%$ between the earliest survey in 1980 and the latest published results in 1988. These patients, and an unknown number who have had incomplete resections, cannot hope to gain any survival benefit in return for the pain and morbidity caused by their operation-indeed this has its own mortality. We can only hope that practice will change as the results are subjected to objective audit. Occasional open and close thoracotomy is to be expected if we are not to deny the prospect of surgical cure on the basis of some indefinite or uncertain preoperative features, but resection should prove feasible in around $95 \%$ of patients subjected to thoracotomy. ${ }^{1-3}$

That surgeons continue to undertake thoracotomy without a thorough preoperative assessment of the mediastinum may in part be due to the fact that computed tomography is not always available; but I suspect that in the main it reflects a lack of experience with mediastinoscopy during their training and confusion about the results of resection for cancers where mediastinal nodes are affected ( $\mathbf{N}_{2}$ disease).

There are many historical publications ${ }^{45}$ reporting five year survival of up to $30 \%$ for patients undergoing resection for $\mathrm{N}_{2}$ disease. These retrospective studies are based on the analysis of pathology reports of patients who have had complete resection, usually ignoring those whose tumours are non-resectable or have been incompletely resected, and often disregarding those who died as a result of the operation. There is the tacit assumption that all these long term survivors would have been denied surgery if the authors had utilised mediastinoscopy. This is not so. Mediastinoscopy will detect only gross, usually widespread, disease of the nodes in the superior mediastinum. These patients often have non-resectable ${ }^{6}$ cancer and have no chance of long term survival. ${ }^{6}$ Even when surgeons have attempted to use mediastinoscopy to select the most favourable group with preoperatively defined $\mathrm{N}_{2}$ disease, ${ }^{78}$ operating on only $10-20 \%$ of those "mediastinoscopy positive" cases, the results are marginal. Although actuarial five year survival in these reports is $9-14 \%$, the numbers are very small and further eroded by perioperative deaths. In contrast, the more subtle $\mathbf{N}_{2}$ disease that eludes mediastinoscopy or computed tomography and is discovered at thoracotomy is associated with a five year survival overall of $20-24 \%^{7-9}$-and $33-41 \%$ if complete resection is possible. ${ }^{79}$

Two papers need to be considered in more detail as they report apparently encouraging results of resection for $\mathrm{N}_{2}$ disease without the use of mediastinoscopy, the authors relying on clinical findings, bronchoscopy, and plain chest radiography for evidence of resectability.

Naruke and his colleagues ${ }^{10}$ report a $19 \cdot 2 \%$ five year survival after surgery in these circumstances. The reported details in the study are incomplete but I would estimate that about $\mathbf{4 8 0}$ patients underwent thoracotomy after this preoperative assessment and were found to have $\mathrm{N}_{2}$ disease. We are told that 426 underwent resection, which was complete in 242 patients. We guess that about 14 patients died after surgery. Although the 24 five year survivors are indeed $19.2 \%$ of those having complete resection, they are only $5 \%$ of those subjected to thoracotomy and few more than those patients whose lives were shortened by operation.

Martini et al ${ }^{11}$ did not use mediastinoscopy and report a $30 \%$ actuarial five year survival after resection for $\mathrm{N}_{2}$ disease. In reality, of 404 patients proceeding with operation after this evaluation, 224 had "unexpected $\mathrm{N}_{2}$ disease" and only 179 had $\mathrm{N}_{2}$ disease predicted at the preoperative assessment. Of the latter, only 32 had complete resection, and the $9 \%$ actuarial survival consists of only two or three patients. Around 34 of the 37 long term survivors come from the unexpected $\mathrm{N}_{2}$ group.

The inevitable conclusion is that the only group of patients with $\mathrm{N}_{2}$ disease who stand to benefit from resection are those whose nodal metastases escape the preoperative evaluation. Meticulous preoperative evaluation of the mediastinum, using mediastinoscopy, will result in a higher resection rate, more complete resections, and worthwhile long term survival. Those surgeons having ready access to computed tomography will be able to reserve mediastinal exploration for patients who have abnormalities on the computed tomogram of the mediastinum. ${ }^{12}$ Those who do not have this facility should consider mediastinal exploration as routine for all patients, except in cases of small peripheral tumours known to be squamous cancers.

Despite careful preoperative evaluation "unexpected $\mathrm{N}_{2}$ disease" will be found in $20-25 \%$ of patients at thoracotomy. ${ }^{23}$ These nodal metastases will be of small volume and often within macroscopically normal nodes. Intraoperative dissection of mediastinal nodes should be routine, and is now recognised by the International Association for the Study of Lung Cancer ${ }^{13}$ as an important step to be taken before resection. It matters less whether 
the surgeon believes that nodes should be resected en bloc as part of the cancer treatment or whether nodal "sampling" is performed as an intraoperative investigation. Without intraoperative nodal dissection we will often underestimate the extent of the disease, fail to perform complete resections, and overestimate the accuracy of our preoperative evaluation.

Surgery remains the only prospect for cure in non-small cell lung cancer, but as surgeons we must not allow this fact to make us inflict thoracotomy and, worse, resection on incurable patients. We must embrace mediastinoscopy and recognise that it is not only a test of exclusion. The appearances suggesting inoperability on a plain chest radiograph, at bronchoscopy, and on a computed tomogram are often of low specificity and often prove to have no basis at mediastinoscopy. If surgeons are seen to be indiscriminate in their approach to thoracotomy, their referring physicians, anxious to save patients futile surgery, will be forced to accept these less specific indices of inoperability, and patients may be inappropriately denied the prospects of surgical care.

PETER GOLDSTRAW

Consultant thoracic surgeon

Royal Brompton National Heart and Lung Hospital, London SW3 6NP

Reprint requests to: $\mathrm{Mr}$ Goldstraw
1 Pearson FG, Nelems JM, Henderson RD, Delarue NC. The role of mediastinoscopy in the selection of treatment for bronchial carcinoma with involvement of superior mediastinal lymph nodes. $J$ Thorac Cardiovasc Surg 1972;64:382-90.

2 Fernando HC, Goldstraw P. The accuracy of clinical evaluative intrathoracic staging in lung cancer as assessed by postsurgical pathologic staging. Cancer 1990;65:2503-6.

3 Gaer JA, Goldstraw P. Intraoperative assessment of nodal staging at thoracotomy for carcinoma of the bronchus. Eur $J$ Cardiothorac Surg 1990;4:207-10.

4 Smith RA. The importance of mediastinal lymph node invasion by pulmonary carcinoma in selection of patients for resection. Ann Thorac Surg 1978;25:5-11.

5 Kirsch MM, Kahn DR, Gago O, Lampe I, Fayos JN, Prior M, et al. Treatment of bronchogenic carcinoma with mediastinal metastases. Ann Treatment of bronchogenic
Thorac Surg 1971;12:11-21.

6 Gibbons JRP. The value of mediastinoscopy in assessing operability in carcinoma of the lung. Br $J$ Dis Chest 1972;66:162-6.

7 Pearson FG, Delarue NC, Ilves R, Todd TRJ, Cooper JD. Significance of positive superior mediastinal nodes identified at mediastinoscopy in patients with resectable cancer of the lung. $J$ Thorac Cardiovasc Surg 1982;83:1-11.

8 Coughlin M, Deslauriers J, Beaulieu M, Fournier B, Piraux M, Rouleau J, et al. Role of mediastinoscopy in pretreatment staging of patients with primary lung cancer. Ann Thorac Surg 1985;40:556-60.

9 Watanabe Y, Shimizu J, Oda M, Hayashi Y, Watanabe S, Iwa T. Results of surgical treatment in patients with stage IIIA non-small cell lung cancer. Thorac Cardiovasc Surgeon 1991;39:44-9.

10 Naruke T, Goya T, Tsuchiya R, Suemasu K. The importance of surgery to non-small cell carcinoma of lung with mediastinal lymph node metastasis. Ann Thorac Surg 1988;46:603-10.

11 Martini N, Flehinger BJ. The role of surgery in $\mathrm{N}_{2}$ lung cancer. Surg Clin North Am 1987;67:1037-49.

12 Goldstraw P. CT Scanning in the pre-operative assessment of non-small cell lung cancer. In: Hansen $\mathrm{HH}$, ed. Lung cancer: basic and clinical aspects. Boston: Martinus Nijhoff, 1986:183-99.

13 Consensus Report of the IASLC Working Party on Pretreatment Minimal Staging. Lung Cancer 1991;7:7-9. 